\title{
Transamidation of dimethylformamide during alkylammonium lead triiodide film formation for perovskite solar cells
}

\author{
Michael V. Lee, ${ }^{\text {b) }}$ Sonia R. Raga, Yuichi Kato, Matthew R. Leyden, Luis K. Ono, Shenghao Wang, \\ and Yabing $\mathrm{Qi}^{\mathrm{a}}$ \\ Energy Materials and Surface Sciences Unit (EMSS), Okinawa Institute of Science and Technology Graduate \\ University (OIST), Okinawa 904-0495, Japan
}

(Received 20 May 2016; accepted 30 June 2016)

\begin{abstract}
Perovskite-based solar cells, typically $\mathrm{CH}_{3} \mathrm{NH}_{3} \mathrm{PbI}_{3}$, have reached power conversion efficiencies on par with single crystal silicon solar cells. Perovskite cells prepared with the most common perovskite solvent $N, N$-dimethylformamide (DMF) by different research groups exhibit disparate efficiencies and stability for nominally identical perovskite films. Although the differences can be related to processing conditions, a consistent physical cause for the differences has been lacking. Highly-sensitive time-offlight secondary ion mass spectrometry (TOF-SIMS) reveals significant dimethylamine (DMA) included in perovskite films. TOF-SIMS and x-ray photoelectron spectroscopy results suggest DMA levels ranging from roughly $10-50 \%$. Only the highest levels register as perovskite peak shifts in $\mathrm{x}$ ray diffraction; lower levels are invisible. We propose that methylamine (MA) can react with DMF solvent by transamidation to produce dimethylamine (DMA), which then displaces some MA in perovskite crystals, see Fig. 1 . Transamidation of DMF can be catalyzed by $\mathrm{TiO}_{2}, \mathrm{Al}_{2} \mathrm{O}_{3}$, water, or acid, but in perovskite films transamidation is inhibited by water.
\end{abstract}

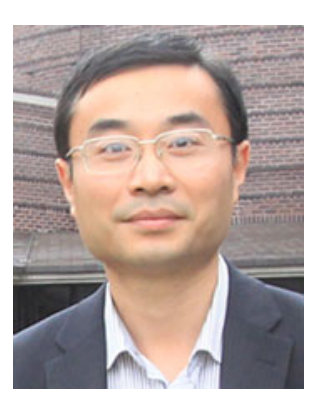

Yabing Qi

Professor Yabing Qi is Head of Energy Materials and Surface Sciences Unit in Okinawa Institute of Science and Technology Graduate University. Dr. Qi received his BS, MPhil, and Ph.D. degrees from Nanjing University, Hong Kong University of Science and Technology, and University of California Berkeley, respectively. Prior to his current appointment, he was a postdoctoral fellow in Princeton University. His research interests include perovskite solar cells, organic electronics, energy storage, surface sciences, advanced material characterization, energy materials and devices. Dr. Qi has co-authored 50+ peer-refereed papers and is the co-inventor of 9 patent applications. As the symposium chair, Dr. Qi organized International Symposium on Organic Electronics (Okinawa, Japan; October 3-5, 2012) and International Symposium on Functional Materials (Okinawa, Japan; January 25-29, 2016). In the 2015 MRS Fall Meeting \& Exhibit, Dr. Qi co-organized Symposium AA: Organic SemiconductorsSurface, Interface and Bulk Doping. In the coming 2016 MRS Fall Meeting \& Exhibit, Dr. Qi will co-organize Symposium ES3: Perovskite Solar Cell Research from Material Properties to Photovoltaic Function. In the coming 2017 MRS Spring Meeting \& Exhibit, as the lead organizer Dr. Qi will organize Symposium ES1: Perovskite Solar Cells-Towards Commercialization.

\section{INTRODUCTION}

Perovskite-based solar cells (PSCs) are currently the leading contender for low-cost solar power. PSCs have far exceeded the power conversion efficiency (PCE) benchmark for commercialization with certified efficiencies exceeding even $20 \% .^{1-6}$ But significant commercialization barriers remain-most notably improving reproducibility and stability. ${ }^{5,7}$ Diverse strategies have improved film morphology of methylammonium lead halide $\left(\mathrm{MAPbX}_{3}\right)$ perovskites, e.g., increasing crystal

\footnotetext{
Contributing Editor: Tao Xie

a) Address all correspondence to this author.

e-mail: Yabing.Qi@OIST.jp

b) Current address: Department of Chemistry and Biochemistry, Northern Arizona University, 700 S Osborne Dr., PO Box 5698, Flagstaff, Arizona, USA 86011.

DOI: $10.1557 /$ jmr.2016.272
}

grain size (correlated to the strength of x-ray diffraction peaks) and film uniformity (measured by atomic force microscopy). ${ }^{8-10}$ However, improved morphology has not directly translated into improved PCE or reduced perovskite degradation, suggesting that the chemical nature of a film plays a significant role. Some recent recordholding perovskite solar cells reduced ${ }^{11}$ or eliminated ${ }^{2}$ $N, N$-dimethylformamide (DMF) and showed corresponding improvement in reproducibility and stability, suggesting that DMF may be related to the underlying causes.

Covalent chemical reactions have already been proposed to be involved in perovskite degradation, but only with respect to reactions with water or oxygen. ${ }^{12-14}$ When considering the reactivity of many components present in perovskite solar cells, such as $\mathrm{TiO}_{2},{ }^{15-17}$ DMF, ${ }^{18,19} \mathrm{MAI},{ }^{20} \mathrm{PbI}_{2}$, water, ${ }^{21}$ or $\mathrm{HI},{ }^{22}$ we wondered whether additional covalent chemical reactions might 
be at work during perovskite formation. We turned to time-of-flight secondary ion mass spectrometry (TOF-SIMS), the chemical microscope, to identify changes in chemical composition of perovskite films.

We present a reaction of DMF that occurs during perovskite film formation, but that has gone un-noticed until now. TOF-SIMS identifies dimethylamine (DMA) after film formation, which we propose is a product of transamidation of DMF (Fig. 1). DMA is present in films formed by two representative methods of perovskite solar cell film preparation that use DMF (two-step sequential deposition and one-step spin-coating), suggesting that the reaction is generally applicable when DMF is used. But DMA is not present in perovskite formed without DMF (single crystal, and solvent-less vapor deposition of perovskite films), correlating with improved stability when DMF is not used. We confirmed the presence of DMA by x-ray photoelectron spectroscopy (XPS) and

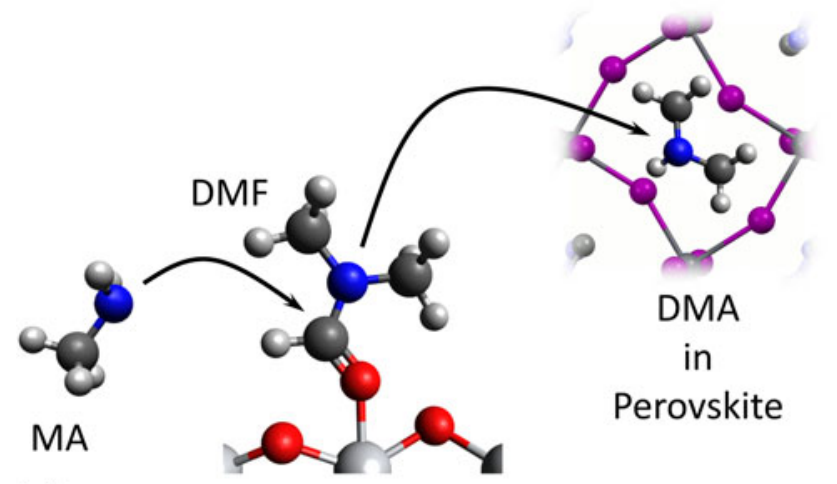

(a)

(b)

$$
\mathrm{DMF}+\mathrm{MA} \stackrel{\text { acid } / \mathrm{TiO}_{2} / \mathrm{H}_{2} \mathrm{O}}{\longrightarrow} \mathrm{NMF}+\mathrm{DMA}
$$

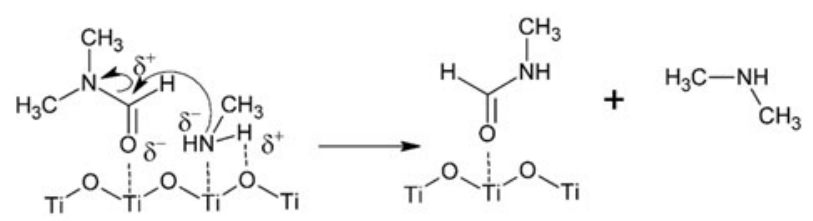

(c)

d)

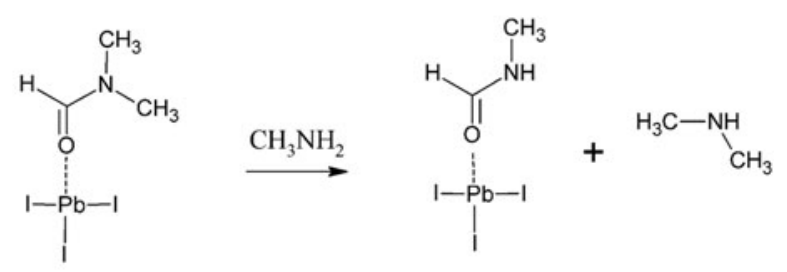

FIG. 1. Catalyzed transamidation produces DMA from DMF that is incorporated into perovskite crystals. (a) In the environment of perovskite solutions methylamine can attack the carbonyl carbon of DMF, displacing DMA. DMA can then be incorporated in to perovskite crystal. (b) Catalyzed transamidation reaction between DMF and methylamine. (c) Mechanism for transamidation of DMF by $\mathrm{TiO}_{2}$ catalyst. (d) Corresponding proposed reaction catalyzed by $\mathrm{PbI}_{2}$ starting from the $\mathrm{DMF} * \mathrm{PbI}_{2}$-complex.
X-ray diffraction (XRD), and suggest how DMA might influence stability or degradation.

\section{EXPERIMENTAL}

\section{A. Materials}

Lead(II) iodide (99\%), lead(II) chloride (98\%), and DMF (99.8\%, anhydrous), and aqueous of $\mathrm{H}_{3} \mathrm{PO}_{2}$ $(9.14 \mathrm{M})$ were purchased and used as received from Sigma-Aldrich. Methylammonium iodide was synthesized from $33 \mathrm{wt} \%$ methylamine in absolute ethanol (Aldrich) and hydroiodic acid (Tokyo Chemical Industry Co., Ltd., $57 \mathrm{wt} \%$ ) according to literature procedure and purified by recrystallization. ${ }^{23}$ Formamidinium iodide (FAI) was purchased and used as received from Dyesol.

Fluorine-doped tin oxide (FTO) films on $2 \mathrm{~mm}$ thick glass substrates (TEC-7, Pilkington, UK) were coated by spray pyrolysis of $\mathrm{TiO}_{2}$ from titanium(IV)isopropoxide (97\%, Aldrich) and acetylacetone (99\%, Sigma-Aldrich) in anhydrous ethanol, according to literature procedure. Silicon wafers (SAMCO Inc, Japan) were n-type, Sb-doped, $0.013 \Omega$-cm.

\section{B. Perovskite preparation}

The perovskites analyzed in this work were prepared by the following methods: (i) single crystal growth by aqueous solution (no DMF); (ii) perovskite film preparation by two-step sequential deposition-dipping $\mathrm{PbI}_{2}$ films into MAI solution (DMF present), which were chemically analyzed by TOF-SIMS and were also confirmed to be similar to the literature ${ }^{11}$ by fabricating and characterizing solar cells; (iii) spin-coated perovskite film preparation under several processing conditions (Table I) using solutions with a 3:1 ratio $\mathrm{MAI}: \mathrm{PbI}_{2}$ in $\mathrm{DMF}$, which is the same ratio used in some recent high-performing $\mathrm{PSCs}^{3}$; (iv) film preparation by chemical vapor deposition (no DMF); and (v) film preparation by hybrid deposition under vacuum (no DMF).

\section{Solution preparation of crystals of $\mathrm{MAPbl}_{3}$ (no DMF)}

Aqueous hydrogen iodide $(6.8 \mathrm{~mL}, 7.58 \mathrm{M})$ and aqueous of $\mathrm{H}_{3} \mathrm{PO}_{2}(1.7 \mathrm{~mL}, 9.14 \mathrm{M})$ were mixed. The mixed solution was added into a $200 \mathrm{~mL}$ 2-necked round bottom flask. Nitrogen gas was bubbled through the solution for $1 \mathrm{~min}$. We kept the solution under a nitrogen atmosphere throughout the experiment. The solution was heated to $120{ }^{\circ} \mathrm{C}$ using a stirred oil bath. Subsequently, $\mathrm{PbI}_{2}(462 \mathrm{mg} / \mathrm{mL}, 1 \mathrm{M})$ was added to the solution. $\mathrm{PbI}_{2}$ dissolved to form a yellow solution. MAI $(159 \mathrm{mg} / \mathrm{mL}, 1 \mathrm{M})$ was then also added to the solution. After $4 \mathrm{~h}$, we stopped stirring and let the solution cool to room temperature. After cooling, $1 \mathrm{~mL}$ of 
M.V. Lee et al.: Transamidation of dimethylformamide during alkylammonium lead triiodide film formation for perovskite solar cells

TABLE I. Sample treatment conditions for films presented in this manuscript that were prepared by one-step spin coating.

\begin{tabular}{lllll}
\hline \hline Sample & Spin-coat & \multicolumn{1}{c}{ Environment } & Observation & Bandgap \\
\hline 2000 fresh & $2000 \mathrm{rpm} / 60 \mathrm{~s}$ & Immediately analyzed or annealed & Optically transparent. & $776 \mathrm{~nm}(1.60 \mathrm{eV})$ \\
GB closed & $2000 \mathrm{rpm} / 60 \mathrm{~s}$ & Enclosed in glove box & Cloudy after 5 min. Orange-red tint. & $772 \mathrm{~nm}(1.61 \mathrm{eV})$ \\
GB open & $2000 \mathrm{rm} / 60 \mathrm{~s}$ & Uncovered in glove box & Cloudy after 5 min. Orange-yellow tint. & $777 \mathrm{~nm}(1.60 \mathrm{eV})$ \\
2000 air & $2000 \mathrm{rpm} / 60 \mathrm{~s}$ & Uncovered in ambient & Black and yellow speckle. & $784 \mathrm{~nm}(1.58 \mathrm{eV})$ \\
4000 fresh & $2000 \mathrm{rpm} / 60 \mathrm{~s}+4000 \mathrm{rpm} / 60 \mathrm{~s}$ & Immediately analyzed or annealed & Uniform orange-yellow tint. & $778 \mathrm{~nm}(1.59 \mathrm{eV})$ \\
4000 air & $2000 \mathrm{rpm} / 60 \mathrm{~s}+4000 \mathrm{rpm} / 60 \mathrm{~s}$ & Uncovered in ambient & Immediately dark red upon air exposure. & $784 \mathrm{~nm}(1.58 \mathrm{eV})$ \\
& & & & Sometimes black and yellow speckle over time. \\
\hline \hline
\end{tabular}

2-propanol was gradually added to the solution. After 1 week, black crystals precipitated. We filtered and washed the crystals with anhydrous ethanol. The procedure was modified from the literature. ${ }^{24}$

\section{Two-step perovskite and solar cell confirmation (DMF)}

$\mathrm{PbI}_{2}$ (1 $\mathrm{M}$ in DMF, $70{ }^{\circ} \mathrm{C}$ ) was spin-coated on mesoporous $\mathrm{TiO}_{2} /$ compact $\mathrm{TiO}_{2} / \mathrm{FTO} /$ glass substrates at $500 \mathrm{rpm}$ for $5 \mathrm{~s}$, followed by $6000 \mathrm{rpm}$ for $20 \mathrm{~s}$. After drying for $3 \mathrm{~min}$ at $40{ }^{\circ} \mathrm{C}$ and then $10 \mathrm{~min}$ at $100{ }^{\circ} \mathrm{C}$, the samples were dipped in MAI solution $(10 \mathrm{mg} / \mathrm{mL})$ in IPA and dried by spinning on the spin-coater at $500 \mathrm{rpm}$ for $5 \mathrm{~s}, 1500 \mathrm{rpm}$ for $10 \mathrm{~s}$, and then $3000 \mathrm{rpm}$ for $20 \mathrm{~s}$. The perovskite films were then dried for $15 \mathrm{~s}$ at $150{ }^{\circ} \mathrm{C} .{ }^{11}$ Drying at $150{ }^{\circ} \mathrm{C}$ should remove the remaining DMF and terminate the reactions we discuss in the manuscript. Films were stored under nitrogen until analysis, or in the case of solar cell fabrication, until the hole extraction layer and gold electrodes were deposited as described below.

When devices were fabricated, $59 \mathrm{mM}$ of $2,2^{\prime}, 7,7^{\prime}$-tetrakis ( $N, N^{\prime}$-di- $p$-methoxyphenyl-amine)-9, $9^{\prime}$-spirobifluorene (spiro-MeOTAD), $172 \mathrm{mM}$ 4-tert-butylpiridine (tBP) and $32 \mathrm{mM}$ lithium bis-(trifluoromethylsulfonyl)imide salt in chlorobenzene was spin-coated on the perovskite film as the hole extraction layer and gold was thermally evaporated through a contact shadow mask for the top electrode [Fig. 2(a)]. ${ }^{25}$ Solar cell current-voltage $(i-V)$ response was measured using a Newport Oriel Sol 1A solar simulator (Newport Corp., Bozeman, Montana) with 1-sun (AM $\left.1.5 \mathrm{G}, 100 \mathrm{~mW} / \mathrm{cm}^{2}\right)$ illumination. The intensity varies within $\pm 5 \%$ of the calibrated value, which is comparable to the original article. The $i-V$ curve was measured at a scan rate of $0.1 \mathrm{~V} / \mathrm{s}$ in the reverse direction $(1.2 \mathrm{~V}$ to $0 \mathrm{~V})$.

We found the cells performed comparably based on the characteristics published in the original paper. ${ }^{11}$ Measured power conversion efficiencies were $13.4 \pm 1 \%$ with a champion cell of $14.8 \%$. The average short-circuit current $\left(J_{\mathrm{sc}}\right)$, open-circuit voltage $\left(V_{\mathrm{oc}}\right)$, and fill factor $(\mathrm{FF})$ were $18.5 \mathrm{~mA} / \mathrm{cm}^{2}, 1.04 \mathrm{~V}$, and $69 \%$, respectively, based on statistical analysis of 14 cells [Fig. 2(b)]. Although not reported in the original work, our cells exhibited hysteresis. The average of forward and reverse scans for the highest performing cell was $11.3 \%$.

\section{Preparation, treatment, and annealing of spin-coated MAI: $\mathrm{Pbl}_{2}$ films (variable DMF)}

We prepared solutions of 3:1 molar ratio of MAI: $\mathrm{PbI}_{2}$ in DMF. The $\mathrm{PbI}_{2}$ molarity in the solution was $0.87 \mathrm{~mol} / \mathrm{L}$. The solutions were spin-coated on $12 \times 12 \mathrm{~mm}$ compact $\mathrm{TiO}_{2}$-coated $2 \mathrm{~mm}$ thick FTO/glass substrates at $2000 \mathrm{rpm}$ for $60 \mathrm{~s}$ with or without a second step of $4000 \mathrm{rpm}$ for $60 \mathrm{~s}$. After preparing the films on the substrates, samples were carefully subjected to a variety of conditions before annealing. The conditions were: spin-coating at $2000 \mathrm{rpm}$ for $60 \mathrm{~s}$ and starting annealing or analysis in less than $5 \mathrm{~min}$ from spin-coating (2000 fresh); spin-coating at $2000 \mathrm{rpm}$ for $60 \mathrm{~s}$ and then enclosing in a Petri dish in the $\mathrm{N}_{2}$ glove box for 25 $\min (G B$ closed); spin-coating at $2000 \mathrm{rpm}$ for $60 \mathrm{~s}$ and then placing the sample in an open Petri dish in the $\mathrm{N}_{2}$ glove box for $25 \mathrm{~min}$ (GB open); spin-coating at $2000 \mathrm{rpm}$ for $60 \mathrm{~s}$, and then placing the sample in an open Petri dish in class 100 clean room environment with fluorescent lighting for $25 \mathrm{~min}$ (2000 air); spin-coating at $2000 \mathrm{rpm}$ for $60 \mathrm{~s}$, followed by $4000 \mathrm{rpm}$ for $60 \mathrm{~s}$, then immediately analyzing or annealing (4000 fresh); and spin-coating at $2000 \mathrm{rpm}$ for $60 \mathrm{~s}$, followed by $4000 \mathrm{rpm}$ for $60 \mathrm{~s}$, and then placing the sample in an open Petri dish in class 100 clean room environment with fluorescent lighting for $25 \mathrm{~min}$ (4000 air). At the end of preparation and any treatment, samples were transferred to the analysis instrument and analysis was begun in less than $5 \mathrm{~min}$ from the end of spin-coating (2000 fresh or 4000 fresh) or the end of the respective environmental treatment. Samples from the glove box were transferred in a sealed container to maintain the nitrogen environment and covered in aluminum foil to protect the samples from light. Identically prepared samples were annealed on a hotplate in a nitrogen glove box or in the open lab before analysis to mimic the variety of PSC annealing conditions in the literature (Table I).

\section{CVD preparation of $\mathrm{FAPbl}_{3}$ films (no DMF)}

Perovskite films were grown in a two-step process where lead chloride was first deposited onto substrates, 


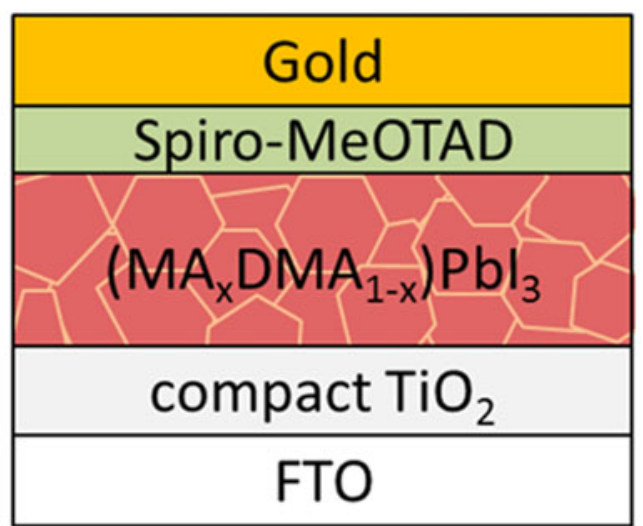

(a)

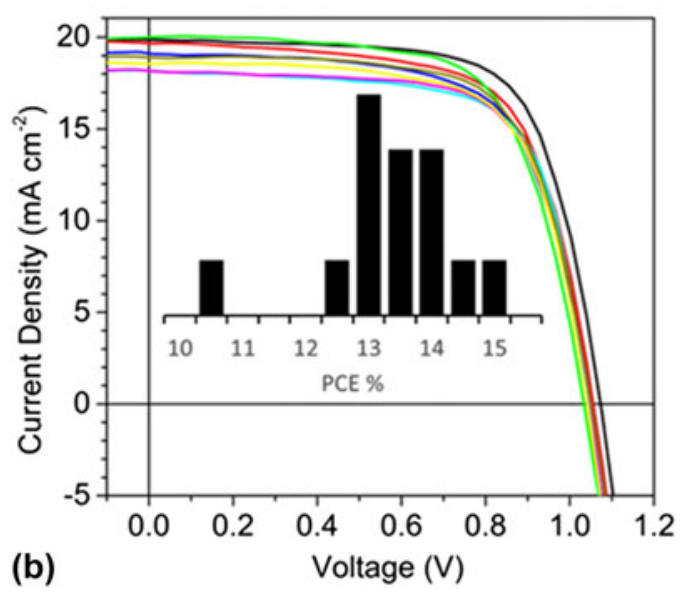

FIG. 2. Transamidation of DMF produces DMA that is incorporated into high-efficiency PSCs. (a) PSC structure of FTO/compact- $\mathrm{TiO}_{2} /$ $\mathrm{MAPbI}_{3}$ (two-step solution deposition)/spiro-MeOTAD/Au. (b) Response curves and histogram of PCE percentages for solar cells that have DMA incorporated into the perovskite. $V_{\mathrm{oc}}, J_{\mathrm{sc}}$, and Fill Factor averages with standard deviations were respectively, $1.04 \pm 0.02 \mathrm{~V}$, $18.5 \pm 1.3 \mathrm{~mA} / \mathrm{cm}$, and $69.3 \pm 1.9$. One high-efficiency cell reached $14.8 \%$ PCE.

followed by CVD deposition of FAI which converted the film to perovskite. ${ }^{26}$ Perovskite films were prepared by depositing a $100 \mathrm{~nm}$ layer of lead chloride onto substrates by thermal evaporation (at $2.0 \times 10^{-2} \mathrm{~Pa}$, approximately $0.1-0.4 \AA / s$, using $\mathrm{PbCl}_{2}$ powder). Substrates predeposited with $\mathrm{PbCl}_{2}$ were loaded into a 2zone CVD furnace, where the first zone was loaded with $\sim 1 \mathrm{~g}$ of solid FAI powder and the second zone with substrates. Substrates were ramped up to $120^{\circ} \mathrm{C}$, and then FAI was ramped to $180{ }^{\circ} \mathrm{C}$.

\section{Vacuum preparation of $\mathrm{MAPbl}_{3}$ films using hybrid deposition (no DMF)}

$\mathrm{MAPbI}_{3}$ films were prepared by thermal evaporation of $\mathrm{PbI}_{2}$ and MAI in a custom hybrid deposition method ${ }^{27,28}$ or multi-source multi-layer deposition vacuum chamber. To achieve both thick films and uniformity, two wide mouth crucibles are used for evaporating the source materials. A heat shield between the two sources minimizes thermal "cross-talk" by blocking radiative heat transfer. Two thickness monitors independently monitor the evaporation rate of $\mathrm{PbI}_{2}$ and MAI during hybrid deposition. Direct flux of MAI is blocked by a shutter to improve film uniformity. We optimized the perovskite deposition conditions by preparing several batches of perovskite films grown with different relative nominal rates of $\mathrm{PbI}_{2}$ : MAI deposition to identify the evaporation conditions that give strong XRD peaks for the perovskite structure, while also minimizing the peak intensities for MAI and $\mathrm{PbI}_{2}$.

\section{Sample analysis}

\section{Time-of-flight secondary ion mass spectrometry}

TOF-SIMS data were obtained using a PHI Trift $\mathrm{V}$ nanoTOF (ULVAC-PHI Inc., Japan) instrument using $60 \mathrm{keV} \mathrm{Bi}_{3}{ }^{++}$(30 keV applied potential) ion beam. The DC current was $2.0 \mathrm{nA}$ for the analysis beam. Raster scans of $100 \times 100 \mu \mathrm{m}$ were used for spectra and image collection. An argon cluster beam $\mathrm{Ar}_{2500}{ }^{+}$at $10 \mathrm{keV}$ scanned over $400 \times 400 \mu \mathrm{m}$ areas at $3.5 \mathrm{nA}$ was used for sputtering during depth profiling. Both positive and negative spectra were acquired for single-crystal $\mathrm{MAPbI}_{3}$, CVD-prepared $\mathrm{FAPbI}_{3}$, and two-step solution-processed $\mathrm{MAPbI}_{3}$ films.

\section{X-ray diffraction with in situ annealing}

We measured XRD with a Bruker D8 Discover instrument (Bruker AXS K. K., Tokyo, Japan) using $\mathrm{Cu} \mathrm{K}_{\alpha}$ source X-rays. The instrument is equipped with Pathfinder 0D and Vantec-500 2D detectors, in addition to an AntonPaar DHS-1100 heating stage. Samples were annealed in air on the XRD heating stage so that spectra could be obtained in situ. Surface temperatures for the annealing process were calibrated on a $\mathrm{TiO}_{2} / \mathrm{FTO} /$ glass substrate using a low-mass, thin wire, type $\mathrm{K}$ thermocouple pressed against the substrate's top surface. Each surface temperature was paired to the stage temperature for a specific ramp rate. High-resolution XRD $\theta-2 \theta$ scans were acquired prior to annealing and also after ramping to $110{ }^{\circ} \mathrm{C}$.

High and low resolution spectra provided accurate peak identification while also minimizing atmospheric exposure. Peak positions were determined with $0.02^{\circ}$ sampling and dwell times of $200 \mathrm{~ms}$ between 5 and $65^{\circ}$. On some sample replicates, quick $0.1^{\circ}$ resolution scans with dwell times of $100 \mathrm{~ms}$ allowed sample scanning to complete in less than $5 \mathrm{~min}$ from preparation and within only a two minutes of atmospheric exposure.

For in situ XRD during annealing, quick scans at $0.1^{\circ}$ sampling intervals and shorter ranges of $5-32^{\circ}$ or $7-17^{\circ}$ minimized the temperature ramping time. Samples were 
annealed in air in the dark on the XRD heating stage with a constant temperature ramp from room temperature to $110{ }^{\circ} \mathrm{C}$ (calibrated) at which point a fine XRD scan was measured again. The samples were further annealed at (nominal) $110{ }^{\circ} \mathrm{C}$, or alternatively heated to $130{ }^{\circ} \mathrm{C}$ and annealed, in air for at least $20 \mathrm{~min}$. Temperature ramp rates of $2^{\circ}$ per minute are presented in the manuscript, but similar results were obtained with ramp rates of $60^{\circ}$ per minute. Crystallographic changes over time with air exposure were also recorded for some samples. From a single solution, the spectra were very similar as long as the time was minimized for getting the samples mounted on the XRD stage. As long as the ratios among $\mathrm{PbI}_{2}$, MAI, and DMF were maintained, then the results were comparable for different solutions.

\section{UV-visible spectroscopy}

Absorbance spectra were measured with a Thermo Scientific Evolution 600 UV-vis spectrometer (Thermo Electron Scientific Instruments LLC, Madison, Wisconsin) in transmission mode. Transmission for spin-coated films was compared to transmission of a sample with only mesoporous $\mathrm{TiO}_{2}$ and without any perovskite.

\section{X-ray photoelectron spectroscopy}

XPS analysis was performed using a Kratos Ultra DLD instrument (Kratos Analytical Ltd., Manchester, United Kingdom) with monochromated $\mathrm{Al} \mathrm{K} \mathrm{K}_{\alpha}(h v=1486.6 \mathrm{eV})$ $\mathrm{x}$-rays and a multi-channel plate detector with a $180^{\circ}$ hemispherical analyzer. Binding energy was calibrated against the $\mathrm{Au} 4 f(83.95 \mathrm{eV})$ and $\mathrm{Cu} 2 p(932.65 \mathrm{eV})$ peaks on standard samples. ${ }^{29}$ Survey and fine scan spectra were acquired for each sample. If the films were electrically insulating, charge compensation was used. The atomic ratios were calculated based on integrated area under the XPS peaks and the sensitivity factors from the Kratos element library for CasaXPS. The atomic percent of oxygen, carbon, nitrogen, and iodine were divided by the percent of lead, enabling direct comparison to perovskite stoichiometric ratios. Integration of I $3 d$ peaks was $76 \%$ of that for integration of I $4 d$ peaks. The intensity of the I $4 d$ peak was closer to what was expected based on stoichiometry, so it was used instead of the I $3 d$ peaks. In perovskite materials there may be a significant deviation from standard sensitivity factors for one or both of the iodine peaks. Only I $3 d$ data were acquired for 2000 fresh and $G B$ closed spectra so for these samples the iodine intensity was scaled to compare to I $4 d$ data. If the I $3 d$ values are actually more correct, then the fundamental conclusions of the manuscript would be unchanged, but it would indicate that iodine can be lost independent of MA. In that case, the chemistry would be even more complicated than what is presented here.

\section{RESULTS}

\section{A. TOF-SIMS identification of DMA and NMF}

TOF-SIMS can conclusively identify molecular components in films or on surfaces. Primary ions impact a surface, ejecting secondary ions with specific mass-tocharge ratios $(\mathrm{m} / \mathrm{z})$ representative of the surface composition. Gentle ionization by cluster ions enhances the signal from both the molecular ion and also the fragments, allowing identification of each molecule ejected from the surface. Time-of-flight mass accuracy allows exact determination of the molecular formula. The pattern of relative abundances for each fragment ion provides a mass spectral fingerprint that eliminates any remaining ambiguity with respect to an ion's identity.

We first show the TOF-SIMS spectra of single-crystal perovskite $\left(\mathrm{SC}-\mathrm{MAPbI}_{3}\right)$ grown in a DMF-free solution as an example of the mass spectrum of pure perovskite [Fig. 3(a)]. The spectrum shows a strong peak from the methylammonium parent ion $(\mathrm{m} / \mathrm{z}=32.049)$ and its

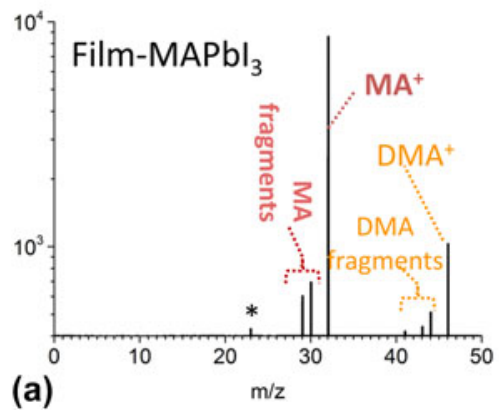

(a)

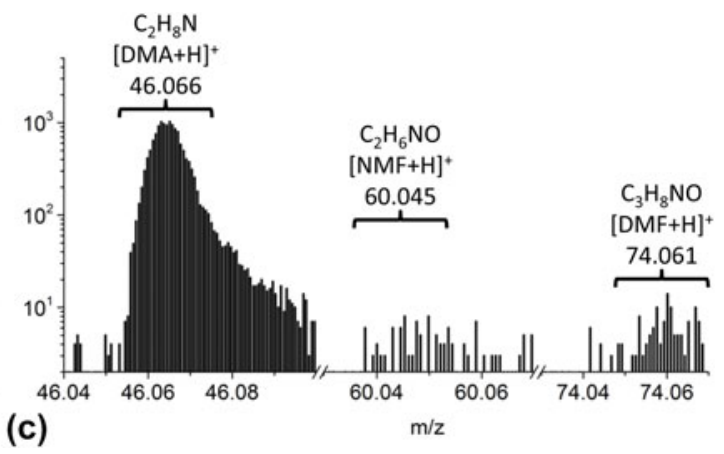

(c)

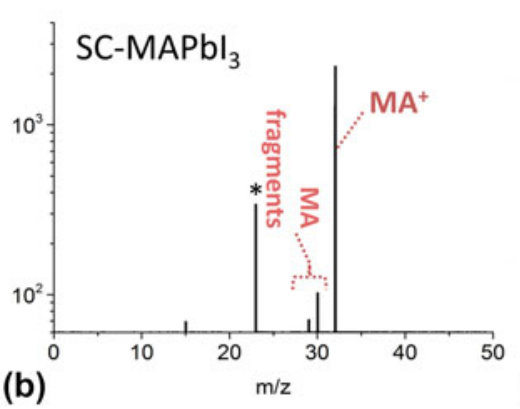

(b) without DMF exhibiting no DMA-related peaks; (b) Two-step DMF solution-processed, MAPbI $_{3}$ films, including both DMA and methylammonium (MA) ions; and (c) Mass spectral peaks from the film samples at the exact masses of DMA, DMF, and the byproduct of DMF transamidation, $\mathrm{N}$-methylformamide (NMF). The * denotes sodium ions that are present at trace levels, but that sometimes appear prominently due to a high ion yield for sodium. 
associated fragments. The spectrum is clean with only the expected peaks.

We fabricated films with a two-step process-identical to those used for solar cells, which performed the same as the solar cells in the published literature ${ }^{11}$-and analyzed them by TOF-SIMS to understand their chemical composition. Spectra from the two-step perovskite films include the same MAI peaks from the single-crystal spectrum [Fig. 3(b), Film-MAPbI ${ }_{3}$ ]. However, DMF solvent $(\mathrm{m} / \mathrm{z}=74.016)$ can also be observed at a low intensity demonstrating that DMF can still remain after annealing.

The biggest surprise, however, is a strong peak from $\left[\mathrm{C}_{2} \mathrm{H}_{8} \mathrm{~N}\right]^{+}(\mathrm{m} / \mathrm{z}=46.065)$. The mass and fragments only match database spectra for DMA. ${ }^{30}$ Another unexpected molecule, $N$-methylformamide (NMF) [Fig. 3(c)] is also present at a similar level to DMF. DMA and NMF are the products of transamidation. Decomposition or carbonylation (see Supplementary Material section and Figs. S1-S3) could also produce DMA from DMF, but would not produce NMF. Transamidation produces a significant amount of DMA in perovskite solar cells.

The two-step method used less DMF than previous methods and produced record PSCs that are still among the best examples in the literature. However, they include a significant impurity-DMA. Assuming similar ionization efficiencies for both amines, a rough estimate might suggest $10 \%$ DMA relative to MA. This is a significant contribution to the composition of the perovskite films.

\section{B. Crystal phases in perovskite films}

Residual DMF produced different crystal structures, or phases, but they were only apparent before the films were annealed to at least $120{ }^{\circ} \mathrm{C}$. We performed in situ XRD analysis on samples with excess DMF and methylamine to more clearly observe the effects of transamidation. We prepared films with excess MAI (3:1 MAI:PbI ${ }_{2}$ ) similar to some of the first high-efficiency perovskite solar cells. ${ }^{3}$ We acquired XRD spectra before and after annealing [Figs. 4(a) and 4(b), also S2]. Films were spincoated at low speed (labeled 2000 fresh and 2000 air) to reduce evaporation of DMF or at higher speed (labeled 4000 fresh) to enhance evaporation of DMF. This allowed us to compare the effect of DMF. The effect of air exposure over $30 \mathrm{~min}$ was studied in samples labeled 2000 air, the rest were processed under dry $\mathrm{N}_{2}$. Other conditions after the spin-coating were also studied (Tables I and S1). Our spin-coated films show clear differences among all conditions within $30 \mathrm{~min}$; the differences were captured by UV-vis absorption spectra (Fig. S4).

XRD revealed four principal crystal structures (Figs. 4 and S2). Three of the structures observed by XRD are present prior to annealing and have been described previously: perovskite, water complex, and DMF complex. The perovskite structure, which we identify in the

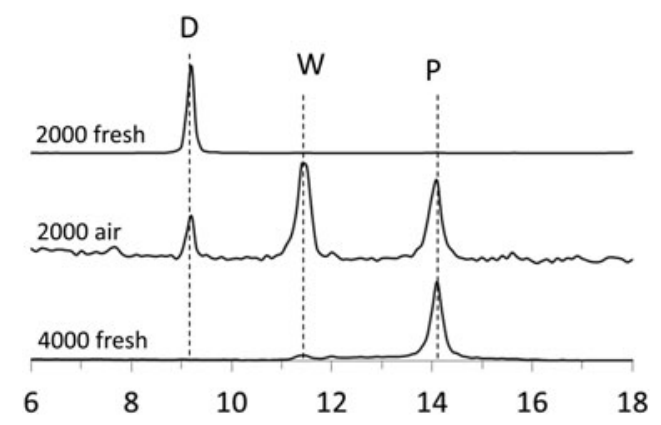

(a) $2 \theta /$ degrees

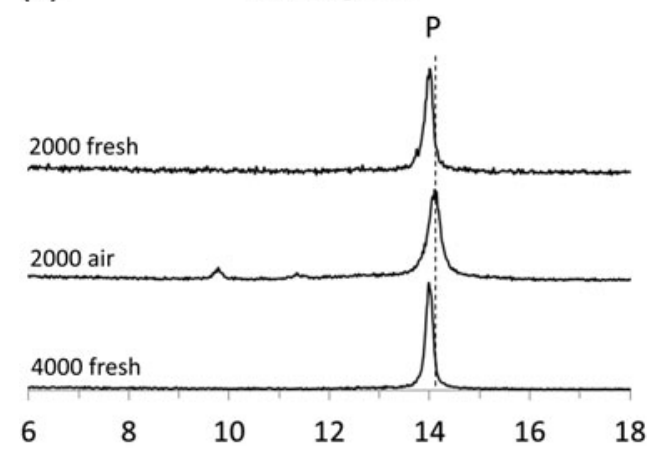

(b) $2 \theta /$ degrees

FIG. 4. XRD spectra of films prepared with excess DMF and MAI (a) before annealing and (b) after annealing. P, D, and W mark respective peak positions for $\mathrm{MAPbI}_{3}$ perovskite, $\mathrm{DMF}^{*} \mathrm{PbI}_{2}$ complex, and (MA) PbI $_{6} * 2 \mathrm{H}_{2} \mathrm{O}$ complex. Sample 2000 fresh was spin-coated at $2000 \mathrm{rpm}$ before measurement and annealing. Sample 2000 air was prepared at $2000 \mathrm{rpm}$ and then left in ambient air before XRD and annealing. Sample 4000 fresh was spin-coated at $4000 \mathrm{rpm}$ to remove DMF solvent. The final perovskite peaks shift to a lower angle unless the films are exposed to air.

figures with "P", is well known in the literature. The $\mathrm{MAPbI}_{3}$ perovskite structure has two main peaks at 14.1 and $28.3^{\circ}$ when measured by $\mathrm{Cu} \mathrm{K}_{\alpha} \mathrm{X}$-rays, corresponding to a $d$-spacing of $6.28 \AA{ }^{24,31}$ The water complex, which we have marked with "W", refers to (MA) $)_{4} \mathrm{P}$ $\mathrm{bI}_{6} * 2 \mathrm{H}_{2} \mathrm{O} .{ }^{32-34}$ The water complex requires 4 methylammonium ions to each lead atom and appears in films exposed to humid air when excess MAI is present [W; Figs. 4(c) and S5]. The third known structure is a 1:1 complex between the solvent DMF and $\mathrm{PbI}_{2}$ $\left(\mathrm{DMF} * \mathrm{PbI}_{2} \text {-complex }\right)^{33}$; we marked its peaks with "D".

\section{Phase transformations}

In situ XRD during the annealing process [Fig. 5(a)], shows the phase transformations in the films prepared with excess DMF and MAI. We found that the basic structures in the perovskite films transform through two discrete processes during annealing, one DMF-related, and the other water-related [Fig. 5(c)]. Both of the processes and their related structures can be observed during annealing of a freshly prepared film spin-coated at 2000 rpm [Fig. 5(b)]. 
(a)

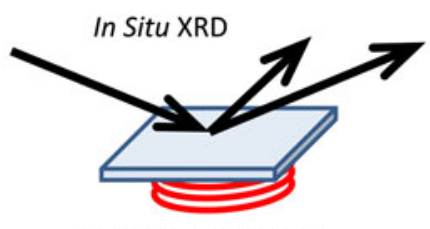

Temperature Ramp

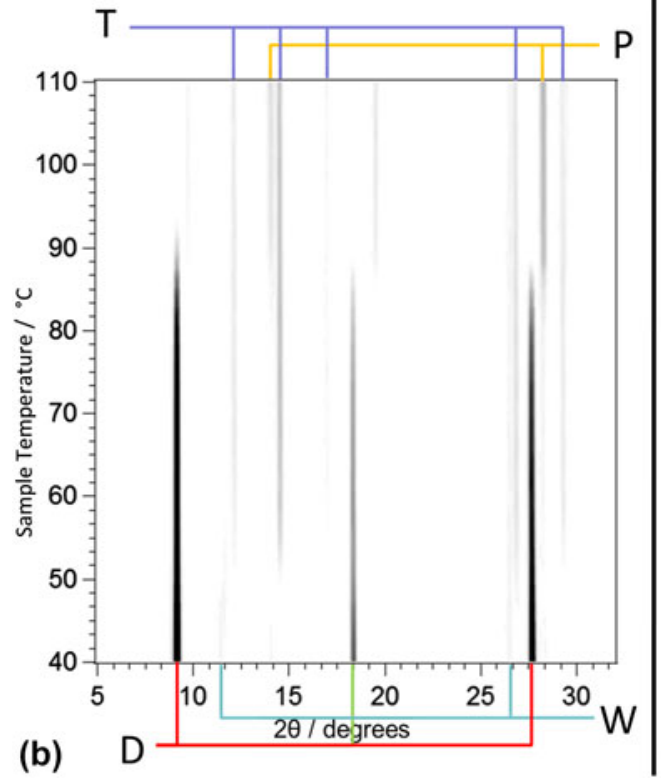

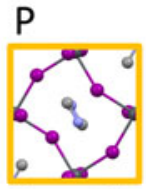

Perovskite

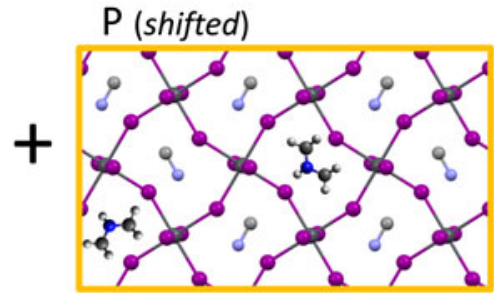

$(\mathrm{MA})_{x}(\mathrm{DMA})_{1-x} \mathrm{Pbl}_{3}$

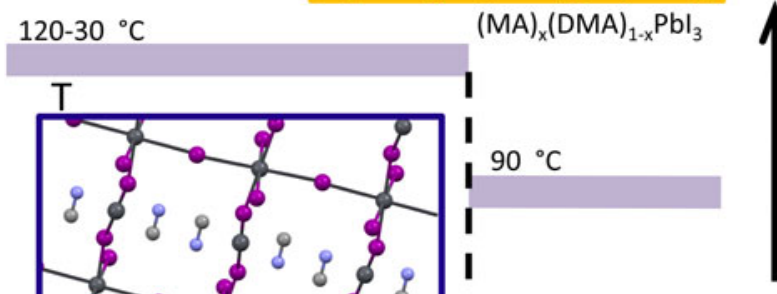

D

Distorted Perovskite

(not stable at $25^{\circ} \mathrm{C}$ )

$45-50{ }^{\circ} \mathrm{C}$
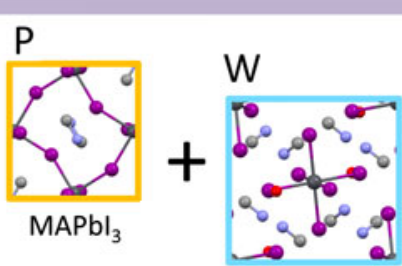

$(\mathrm{MA})_{4} \mathrm{Pbl}_{6} * 2 \mathrm{H}_{2} \mathrm{O}$

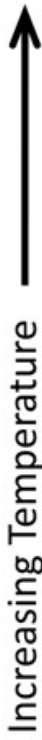

(c)

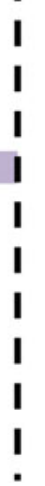

FIG. 5. Controllable transitions between structures in perovskite films. (a) Graphic showing the in situ XRD setup. The samples are heated from the rear similar to typical annealing conditions, while XRD spectra are repeatedly scanned at each temperature. (b) In situ XRD spectrum versus temperature for a sample spin-coated at $2000 \mathrm{rpm}$ and immediately annealed (2000 fresh in Fig. 4). Horizontal axis is $2 \theta$ angle. Vertical axis shows annealing temperature. Grayscale value is XRD intensity. Crystal structure transitions occur at around $40-55^{\circ} \mathrm{C}$ and $85-95{ }^{\circ} \mathrm{C}$, observable by the disappearance of some peaks and appearance of others. (c) Diagram of the structural transitions with water-complex processes on the left and DMFcomplex processes on the right.

During annealing a transition is observed at around $85-95^{\circ} \mathrm{C}$. This DMF-related transition is clearly observed by in situ XRD for films that were annealed with residual DMF [Figs. 4(b) and S6]. When DMF was not retained in the film or not used (Figs. S7 and S8), this transition is minimized or eliminated. A transition at this temperature can explain why temperatures higher than $90^{\circ} \mathrm{C}$, often $100{ }^{\circ} \mathrm{C}$, have been preferred for successful annealing of perovskites. ${ }^{12-14,25,35-40}$ At around $90{ }^{\circ} \mathrm{C}$, the DMF complex (D) disappears concomitant with the appearance of perovskite peaks [P, Fig. 5(b)]. A new minor component also appears that is discussed in the Supplementary Material (Fig. S2). Curiously, the perovskite peaks that appear during this transition occur closer to 14.0 degrees rather than the 14.1 degrees that is typical for perovskite. A 0.1 degree shift is consistent with a slightly larger crystal unit cell, similar to what is observed when some methylammonium is replaced by formamidinium, ${ }^{24,31,41}$ which has a molecular size similar to DMA. DMA is naturally incorporated as a minor component in PSC films in the same fashion as MA, ethylammonium, or formamidinium. $^{41,42}$

During annealing the lower temperature transition occurs at $40-55{ }^{\circ} \mathrm{C}$, as part of the water-related process. The water complex (W) merges with the perovskite phase $(\mathrm{P})$ into a new transient structure $(\mathrm{T})$. The $\mathrm{T}$ structure has not been reported in the literature, which is not surprising because it reverts to $\mathrm{P}+\mathrm{W}$ at room temperature. Instability at room temperature makes observation of the structure less likely.

The transient phase (T) is not stable at room temperature and is reversible with heating and cooling (Fig. 6). The transient phase is observed without DMF present, so it is not related to chemical reactions of DMF. When heated to form the transient phase, the film darkens, but reverts to transparency upon cooling [Fig. 6(a)]. XRD shows the return of the $\mathrm{W}$ and $\mathrm{P}$ peaks upon cooling [Fig. 6(b)]. However if the film is heated at $125^{\circ} \mathrm{C}$, for $30 \mathrm{~min}$ - conditions under which both excess water and also excess methylammonium halide can be 


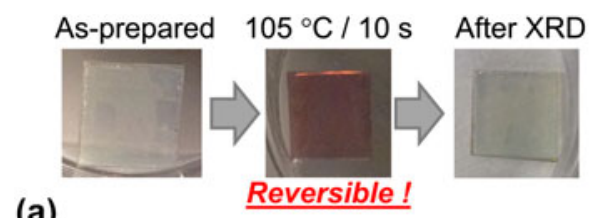

(a)

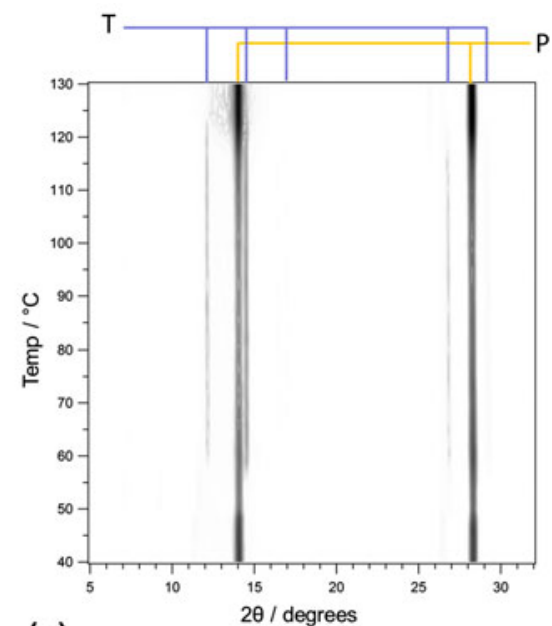

(b)

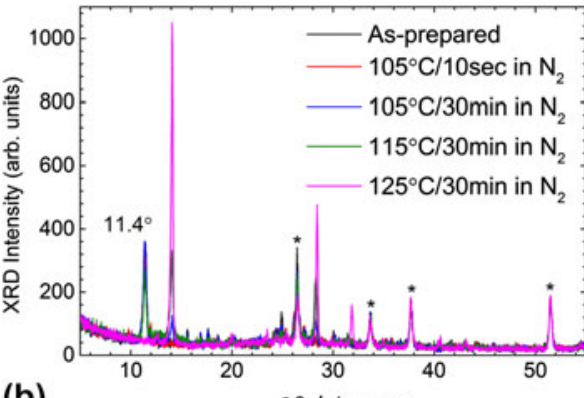

(c)

FIG. 6. Reversible $\mathrm{P}+\mathrm{W} \leftrightarrow \mathrm{T} \leftrightarrow \mathrm{P}$ transition in films with excess MAI is reversible until heated long enough to evaporate excess MAI. (a) Images of reversible conversion after heating and cooling a film with excess MAI prepared by vacuum deposition of PbI $\mathrm{I}_{2}$ and MAI. (b) Ex situ XRD on the film in (a) that was heated to successively higher temperatures, but measured at room temperature. Until the sample is heated above $120{ }^{\circ} \mathrm{C}$ (nominal heating surface temperature $\sim 125{ }^{\circ} \mathrm{C}$ ), the film reverts to the $\mathrm{P}+\mathrm{W}$ crystal structure at room temperature. $*$ denotes $\mathrm{FTO}$ substrate peaks. (c) In situ XRD on a 4000 fresh film with excess MAI, but presumably without excess DMF. The horizontal axis is $2 \theta$ degrees from $\mathrm{XRD}$, while the vertical axis is temperature in ${ }^{\circ} \mathrm{C}$, and the value indicates the intensity of the XRD line (dark $=$ more intense). After annealing above $50{ }^{\circ} \mathrm{C}$ and then to $60{ }^{\circ} \mathrm{C}$, the $\mathrm{P}+\mathrm{W}$ transition to $\mathrm{T}$ is observed. Above $120{ }^{\circ} \mathrm{C}$, the spectrum converges again to a perovskite that is stable at room temperature.

lost ${ }^{25,37,43}$-then films retain only the perovskite structure and are stable at room temperature. The XRD spectrum converges to stable perovskite [Figs. 4(b) and S2]. See Supplementary Material for more information. High-quality, oriented, crystalline films were confirmed by measuring off-axis peaks with 2D-XRD (Fig. S9).

The temperature at which the transient phase appears is already associated with a known phase transition to cubic $\mathrm{MAPbI}_{3} \cdot{ }^{44,45}$ During the transition to cubic, the higher temperature allows bonds to weaken and the inorganic $\mathrm{Pb}-\mathrm{I}$ cage relaxes and allows the methylammonium ions to rotate freely. Alternatively, if the long axis of the orthorhombic Pnma perovskite ${ }^{31}$ unit cell were to lengthen by about $2.3 \AA$ relative to pure $\mathrm{MAPbI}_{3}$, such a structure would produce the main peaks of the transient structure at 12.0 and $14.4^{\circ}$. This expanded structure could house two organic cations. The water complex $\left(4: 1 \mathrm{MA}^{+}: \mathrm{Pb}^{2+}\right)$ might donate MAI to perovskite $\left(1: 1 \mathrm{MA}^{+}: \mathrm{Pb}^{2+}\right)$, merging into an orthorhombic structure with excess alkylammonium cation $\left(2: 1 \mathrm{MA}^{+}: \mathrm{Pb}^{2+}\right.$, Fig. S12). Neither the water complex nor the transient structure could form without excess MAI, which is consistent with our XRD observations.

\section{Chemical characterization by XPS}

The relative composition changes due to MAI loss and DMA insertion by transamidation [Fig. 7(a)] were observed with XPS. For samples similar to those presented in Fig. 4 with a 3:1 starting ratio of $\mathrm{MAI}: \mathrm{PbI}_{2}$ (additional MAI to retain DMF more readily and enhance transamidation), the films initially have five iodine, three carbon, and three nitrogen atoms for each lead atom. These initial atomic ratios relative to lead are marked in Fig. 7(b) as horizontal purple, red, and green bars, respectively, to compare to the compositions as measured by XPS (the solvent DMF is not included). The initial composition deviates significantly from stoichiometric perovskite. However, as others have noted, and as we illustrate here, optimized annealing evaporates excess MAI, moving the composition toward stoichiometric perovskite.

The chemical composition measured by XPS is consistent with transamidation that was revealed by TOF-SIMS and with the transitions observed by XRD. Transamidation will consume one methylamine and replace it with one DMA, moving toward a 2:1 ratio of carbon to nitrogen. During annealing, MAI leaves the sample, ${ }^{25,37,39,43,46}$ lowering the nitrogen, carbon, and iodine content in equal amounts. A combination of these two effects can be observed in Fig. 7.

Increases in carbon relative to nitrogen could have other causes. For instance, methylamine decomposition might leave more carbon than nitrogen; however, carbon content exceeds the carbon amount initially present from MAI [Fig. 7(b)] and methylamine cations are stable up to even $150{ }^{\circ} \mathrm{C}$ (no decomposition of $\mathrm{FA}^{+}$was observed by TOF-SIMS of $\mathrm{FAPbI}_{3}$ prepared by CVD at $150{ }^{\circ} \mathrm{C}$ as shown in Fig. S11). The carbon must come from another source. Adventitious carbon is another possibility. However we strictly limited ambient exposure throughout the 


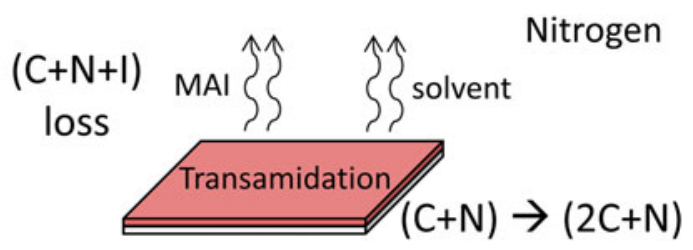

(a)

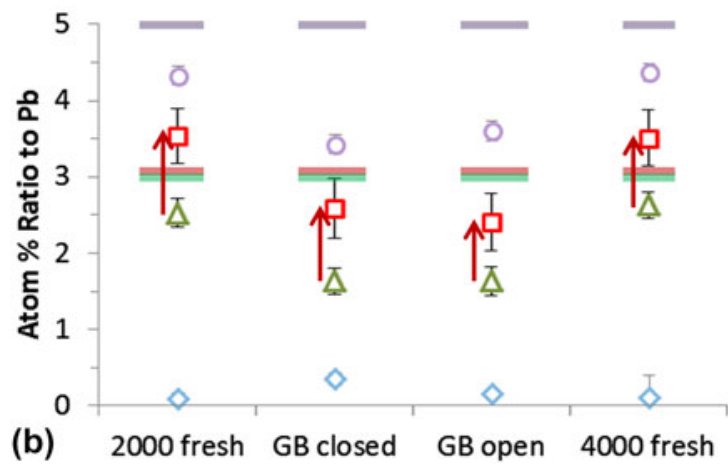

FIG. 7. The effects of MAI loss and transamidation are observed by XPS. (a) MAI loss reduces carbon, nitrogen, and iodine equally, while transamidation increases the amount of carbon relative to nitrogen. (b) XPS atomic ratios. Blue diamonds, red squares, green triangles, and purple circles represent atomic ratios relative to $\mathrm{Pb} 4 f$ for $\mathrm{O} 1 \mathrm{~s}$, $\mathrm{C} 1 \mathrm{~s}, \mathrm{~N} 1 \mathrm{~s}$, and I, respectively based on XPS fine scans for films annealed at $110{ }^{\circ} \mathrm{C}$ in nitrogen. Error bars represent standard deviation. For reference, solid horizontal purple, red, and green bars show the levels of iodine, carbon, and nitrogen in the initial 3:1 solution of MAI: $\mathrm{PbI}_{2}$. Red arrows indicate increased carbon relative to nitrogen. The scale of increase is roughly one carbon (one transamidation) for each $\mathrm{Pb}$ atom. The ratio of MA to DMA can be estimated as $[2(\mathrm{C}-\mathrm{N}) /(2 \mathrm{~N}-\mathrm{C})]$.

experiments, the surface and bulk compositions appeared similar by depth profiling with TOF-SIMS (Fig. S12), and samples left for $30 \mathrm{~min}$ in an open container in the glove box did not have more additional carbon than samples that were not exposed in that manner. In all cases, the carbon increase is proportional to the number of $\mathrm{Pb}$ atoms. The only reasonable explanation is transamidation, possibly with $\mathrm{Pb}$ as the catalyst center [Fig. 1(d)].

\section{DISCUSSION}

We observed DMA, NMF, and DMF, in perovskites that were prepared with DMF as the solvent. Low levels of DMF remain in the films even after annealing to $150{ }^{\circ} \mathrm{C}$. The peak intensities for DMA and NMF are higher than for the solvent, even though neither DMA nor NMF were added. If the ionization efficiencies of both amines are similar, then the ratio of MA:DMA is near 9:1. DMA and NMF are products of DMF transamidation. Transamidation has not been addressed in perovskite solar cell literature. From other literature, transamidation of DMF is catalyzed by $\mathrm{TiO}_{2}$ and $\mathrm{Al}_{2} \mathrm{O}_{3}$, [Figs. 1(a) and 1(b)]. The reaction is accelerated on $\mathrm{TiO}_{2}$ substrates that were prepared with an alcohol and annealed at $500-700{ }^{\circ} \mathrm{C},{ }^{35}$ which is particularly relevant to PSC. ${ }^{3,8,10,11,13,14,25,32,35,36,41,42}$ Alternatively, transamidation can also be catalyzed by water ${ }^{21}$ or an acid (e.g., HI) ${ }^{22}$ (Fig. 1). We believe that transamidation of DMF with MA is the only reasonable explanation for DMA and NMF.

Post-annealing, the relative XPS atom\% for nitrogen and iodine are lower than in the spin-coating solution. This reduction is consistent with depletion of excess MAI by annealing. . $^{2,37,39,43,46}$ However, the carbon content increased relative to nitrogen. Increasing carbon is consistent with transamidation. Transamidation adds carbon by replacing MA (C:N = 1:1) with DMA $(\mathrm{C}: \mathrm{N}=2: 1)$; the extra carbon comes from DMF solvent molecules. Carbon content exceeds the carbon in the original MAI and approaches 1.5 atoms of carbon for each nitrogen atom (50\% MA + 50\% DMA). Two-step perovskite may have $10 \%$ DMA, while DMF solution-prepared perovskite can have up to 50\% DMA content.

When DMF was present, we observed perovskite XRD peaks gradually transform into a $\mathrm{PbI}_{2}-\mathrm{DMF}$ complex. More DMF produced more intense peaks from the complex. After heating above $90{ }^{\circ} \mathrm{C}$, the peaks irreversibly reverted to perovskite peaks. However, the most intense DMF peaks (before annealing) were associated with XRD peak shifts in the perovskite peaks to smaller diffraction angles (after annealing). Similar shifts have been observed when some MA is replaced by FA. ${ }^{35,47}$ Because DMA is similar in size with formamidinium, shifting is consistent with replacement of some MA by DMA in perovskite. No XRD peak shift was observed for our high-efficiency, two-step films that have roughly 10\% DMA (based on TOF-SIMS). This suggests that $\sim 10 \%$ impurities in perovskite can easily hide in highperformance solar cells prepared by methods common in the literature. ${ }^{3,11}$ In contrast, roughly 50\% DMA (based on XPS ratios, Fig. 7) induced a measurable shift of 0.1 degree in XRD. Considering that perovskite with $15 \%$ formamidinium, a similarly sized cation, induced a shift of 0.2 degrees, ${ }^{24,31,41}$ either DMA's effective size is smaller, or not all of the DMA gets incorporated into the perovskite structure. Considering that a film formed from DMAI and $\mathrm{PbI}_{2}$ has a high enough band gap to be mostly transparent and does not exhibit perovskite peaks (Fig. S13), the latter option is more likely.

We observed a reversible transition that this suggests that water could inhibit transamidation between perovskite and a complex with water that dominates if water is present, but disappears after sufficient annealing (Figs. 5 and S5). The complex includes more methylammonium iodide and water relative to lead than perovskite does. Because water is still present as humidity, termination of the reversible transition is more likely due to loss of methylammonium iodide and 
convergence to stoichiometric perovskite (Fig. S7 and S8). Samples exposed to humid air (pre-annealing), which also produced the water-complex transition in XRD did not exhibit the shifted XRD peaks due to DMA incorporation (post-annealing). Perhaps the transient structure protects the perovskite components until annealing converges the composition to stoichiometric perovskite. Transamidation could explain why some published works claim water improves perovskite. ${ }^{3,25,38,48}$

\section{CONCLUSIONS}

TOF-SIMS conclusively identified DMA in highperforming PSC films that were prepared using DMF. We suggest that perovskite researchers consider TOF-SIMS as a powerful and perhaps even necessary tool for chemical characterization of perovskites. Based on TOF-SIMS, XPS, and XRD, we believe transamidation of DMF produces DMA, some of which is inserted into the perovskite crystal. The extent of transamidation and perovskite incorporation of DMA, which could be as high as $\mathbf{5 0 \%}$ for some methods, depend on the environment and annealing conditions. DMA could explain the variability in results in the literature. Although we did not measure the effect that DMA has on perovskite performance, films prepared from pure DMAI $+\mathrm{PbI}_{2}$ are transparent and are not perovskites. This suggests that DMA is detrimental. Finding an alternative solvent that is not chemically reactive will likely further improve thin film perovskite solar cell performance. NMF is a potential alternative.

\section{ACKNOWLEDGMENTS}

This work was supported by funding from the Energy Materials and Surface Sciences Unit of the Okinawa Institute of Science and Technology Graduate University. We thank ULVAC-PHI Inc. (Japan) for measuring samples by TOF-SIMS. We thank Steven D. Aird, the Technical Editor at Okinawa Institute of Science and Technology Graduate University for valuable suggestions.

\section{REFERENCES}

1. A. Kojima, K. Teshima, Y. Shirai, and T. Miyasaka: Organometal halide perovskites as visible-light sensitizers for photovoltaic cells. J. Am. Chem. Soc. 131, 6050 (2009).

2. N.J. Jeon, J.H. Noh, Y.C. Kim, W.S. Yang, S. Ryu, and S.I. Seok: Solvent engineering for high-performance inorganic-organic hybrid perovskite solar cells. Nat. Mater. 13, 897 (2014).

3. H. Zhou, Q. Chen, G. Li, S. Luo, T. Song, H-S. Duan, Z. Hong, J. You, Y. Liu, and Y. Yang: Interface engineering of highly efficient perovskite solar cells. Science 345, 542 (2014).

4. National Renewable Energy Laboratory: Research Cell Efficiency Records (2014). Available at: http://www.nrel.gov/ncpv/images/ efficiency_chart.jpg (accessed 7 Oct 2014).
5. Y. Zhao and K. Zhu: Solution chemistry engineering toward highefficiency perovskite solar cells. J. Phys. Chem. Lett. 5, 4175 (2014).

6. Y. Zhao and K. Zhu: Organic-inorganic hybrid lead halide perovskites for optoelectronic and electronic applications. Chem. Soc. Rev. 45, 655 (2016).

7. H.J. Snaith: Perovskites: The emergence of a new era for low-cost, high-efficiency solar cells. J. Phys. Chem. Lett. 4, 3623 (2013).

8. S. Ito, S. Tanaka, H. Vahlman, H. Nishino, K. Manabe, and P. Lund: Carbon-double-bond-free printed solar cells from $\mathrm{TiO}_{2} / \mathrm{CH}_{3} \mathrm{NH}_{3} \mathrm{PbI}_{3} / \mathrm{CuSCN} / \mathrm{Au}$ : Structural control and photoaging effects. ChemPhysChem 15, 1194 (2014).

9. W. Nie, H. Tsai, R. Asadpour, J-C. Blancon, A.J. Neukirch, G. Gupta, J.J. Crochet, M. Chhowalla, S. Tretiak, M.A. Alam, H-L. Wang, and A.D. Mohite: High-efficiency solution-processed perovskite solar cells with millimeter-scale grains. Science 347, 522 (2015)

10. Q. Chen, H. Zhou, Z. Hong, S. Luo, H-S. Duan, H-H. Wang, Y. Liu, G. Li, and Y. Yang: Planar heterojunction perovskite solar cells via vapor-assisted solution process. J. Am. Chem. Soc. 136, 622 (2014).

11. J. Burschka, N. Pellet, S-J. Moon, R. Humphry-Baker, P. Gao, M.K. Nazeeruddin, and M. Grätzel: Sequential deposition as a route to high-performance perovskite-sensitized solar cells. Nature 499, 316 (2013).

12. J.H. Kim, S.T. Williams, N. Cho, C-C. Chueh, and A.K-Y. Jen: Enhanced environmental stability of planar heterojunction perovskite solar cells based on blade-coating. Adv. Energy Mater. 5, 1401229 (2015).

13. R.S. Sanchez, V. Gonzalez-Pedro, J-W. Lee, N-G. Park, Y.S. Kang, I. Mora-Sero, and J. Bisquert: Slow dynamic processes in lead halide perovskite solar cells. Characteristic times and hysteresis. J. Phys. Chem. Lett. 5, 2357 (2014).

14. T. Leijtens, G.E. Eperon, S. Pathak, A. Abate, M.M. Lee, and H.J. Snaith: Overcoming ultraviolet light instability of sensitized $\mathrm{TiO}_{2}$ with meso-superstructured organometal tri-halide perovskite solar cells. Nat. Commun. 4, 2885 (2013)

15. J. Schneider, M. Matsuoka, M. Takeuchi, J. Zhang, Y. Horiuchi, M. Anpo, and D.W. Bahnemann: Understanding $\mathrm{TiO}_{2}$ Photocatalysis: Mechanisms and materials. Chem. Rev. 114, 9919 (2014)

16. S. Kim and W. Choi: Kinetics and mechanisms of photocatalytic degradation of $\left(\mathrm{CH}_{3}\right)_{n} \mathrm{NH}_{4}-\mathrm{N}^{+}(0 \leq N \leq 4)$ in $\mathrm{TiO}_{2}$ suspension: The role of OH radicals. Environ. Sci. Technol. 36, 2019 (2002).

17. M.A. Henderson: A surface science perspective on photocatalysis. Surf. Sci. Rep. 66, 185 (2011).

18. C.L. Øpstad, T-B. Melø, H-R. Sliwka, and V. Partali: Formation of DMSO and DMF radicals with minute amounts of base. Tetrahedron 65, 7616 (2009).

19. H. Bipp and H. Kieczka: Formamides. In Ullmann's Encyclopedia of Industrial Chemistry (Wiley-VCH Verlag GmbH \& Co. KGaA, Weinheim, 2000).

20. G. Niu, W. Li, F. Meng, L. Wang, H. Dong, and Y. Qiu: Study on the stability of $\mathrm{CH}_{3} \mathrm{NH}_{3} \mathrm{PbI}_{3}$ films and the effect of postmodification by aluminum oxide in all-solid-state hybrid solar cells. J. Mater. Chem. A 2, 705 (2013).

21. T. Lebleu, H. Kotsuki, J. Maddaluno, and J. Legros: Formylation of amines through catalyst- and solvent-free transamidation reaction. Tetrahedron Lett. 55, 362 (2014).

22. C.L. Allen, B.N. Atkinson, and J.M.J. Williams: Transamidation of primary amides with amines using hydroxylamine hydrochloride as an inorganic catalyst. Angew. Chem. Int. Ed. 51, 1383 (2012).

23. M.M. Lee, J. Teuscher, T. Miyasaka, T.N. Murakami, and H.J. Snaith: Efficient hybrid solar cells based on 
meso-superstructured organometal halide perovskites. Science 338, 643 (2012).

24. C.C. Stoumpos, C.D. Malliakas, and M.G. Kanatzidis: Semiconducting tin and lead iodide perovskites with organic Cations: Phase transitions, high mobilities, and near-infrared photoluminescent properties. Inorg. Chem. 52, 9019 (2013).

25. S.R. Raga, M-C. Jung, M.V. Lee, M.R. Leyden, Y. Kato, and Y.B. Qi: Influence of air annealing on high efficiency planar structure perovskite solar cells. Chem. Mater. 27, 1597 (2015).

26. M.R. Leyden, L.K. Ono, S.R. Raga, Y. Kato, S. Wang, and Y.B. Qi: High performance perovskite solar cells by hybrid chemical vapor deposition. J. Mater. Chem. A 2, 18742 (2014).

27. L.K. Ono, S. Wang, Y. Kato, S.R. Raga, and Y.B. Qi: Fabrication of semi-transparent perovskite films with centimeter-scale superior uniformity by the hybrid deposition method. Energy Environ. Sci. 7, 3989-3993, (2014).

28. S. Wang, L.K. Ono, M.R. Leyden, Y. Kato, S.R. Raga, M.V. Lee, and Y.B. Qi: Smooth perovskite thin films and efficient perovskite solar cells prepared by the hybrid deposition method. J. Mater. Chem. A 3, 14631-14641, (2015).

29. J.F. Moulder, W.F. Stickle, P.E. Sobol, and K.D. Bomben: Handbook of X-Ray Photoelectron Spectroscopy: A Reference Book of Standard Spectra for Identification and Interpretation of XPS Data (Physical Electronics, Eden Prarie, MN, 1995).

30. S.E. Stein: Mass spectra. In NIST Chemistry WebBook, NIST Standard Reference Database Number 69, P.J. Linstrom and W.G. Mallard, eds. (National Institute of Standards and Technology, Gaithersburg, 2016).

31. T. Baikie, Y. Fang, J.M. Kadro, M. Schreyer, F. Wei, S.G. Mhaisalkar, M. Graetzel, and T.J. White: Synthesis and crystal chemistry of the hybrid perovskite $\left(\mathrm{CH}_{3} \mathrm{NH}_{3}\right) \mathrm{PbI}_{3}$ for solid-state sensitised solar cell applications. J. Mater. Chem. A 1, 5628 (2013).

32. J.A. Christians, P.A. Miranda Herrera, and P.V. Kamat: Transformation of the excited state and photovoltaic efficiency of $\mathrm{CH}_{3} \mathrm{NH}_{3} \mathrm{PbI}_{3}$ perovskite upon controlled exposure to humidified air. J. Am. Chem. Soc. 137, 1530 (2015).

33. A. Wakamiya, M. Endo, T. Sasamori, N. Tokitoh, Y. Ogomi, S. Hayase, and Y. Murata: Reproducible fabrication of efficient perovskite-based solar cells: X-ray crystallographic studies on the formation of $\mathrm{CH}_{3} \mathrm{NH}_{3} \mathrm{PbI}_{3}$ layers. Chem. Lett. 43, 711 (2014).

34. B.R. Vincent, K.N. Robertson, T.S. Cameron, and O. Knop: Alkylammonium lead halides. Part 1. Isolated $\mathrm{PbI}_{6}{ }^{4-}$ ions in $\left(\mathrm{CH}_{3} \mathrm{NH}_{3}\right)_{4} \mathrm{PbI}_{6} \cdot 2 \mathrm{H}_{2} \mathrm{O}$. Can. J. Chem. 65, 1042 (1987).

35. K. Yan, M. Long, T. Zhang, Z. Wei, H. Chen, S. Yang, and J. Xu: Hybrid halide perovskite solar cell precursors: Colloidal chemistry and coordination engineering behind device processing for high efficiency. J. Am. Chem. Soc. 137, 4460 (2015).

36. S. Colella, E. Mosconi, P. Fedeli, A. Listorti, F. Gazza, F. Orlandi, P. Ferro, T. Besagni, A. Rizzo, G. Calestani,
G. Gigli, F. De Angelis, and R. Mosca: $\mathrm{MAPbI}_{3-x} \mathrm{Cl}_{x}$ mixed halide perovskite for hybrid solar cells: The role of chloride as dopant on the transport and structural properties. Chem. Mater. 25, 4613 (2013).

37. E.L. Unger, A.R. Bowring, C.J. Tassone, V.L. Pool, A. Gold-Parker, R. Cheacharoen, K.H. Stone, E.T. Hoke, M.F. Toney, and M.D. McGehee: Chloride in lead chloridederived organo-metal halides for perovskite-absorber solar cells. Chem. Mater. 26, 7158 (2014).

38. J. You, Y. (Michael) Yang, Z. Hong, T-B. Song, L. Meng, Y. Liu, C. Jiang, H. Zhou, W-H. Chang, G. Li, and Y. Yang: Moisture assisted perovskite film growth for high performance solar cells. Appl. Phys. Lett. 105, 183902 (2014).

39. Y-B. Cheng, Y. Han, S. Meyer, Y. Dkhissi, K. Weber, J. Pringle, U. Bach, and L. Spiccia: Degradation observations of encapsulated planar $\mathrm{CH}_{3} \mathrm{NH}_{3} \mathrm{PbI}_{3}$ perovskite solar cells at high temperatures and humidity. J. Mater. Chem. A 3, 8139 (2015).

40. H. Yu, F. Wang, F. Xie, W. Li, J. Chen, and N. Zhao: The role of chlorine in the formation process of " $\mathrm{CH}_{3} \mathrm{NH}_{3} \mathrm{PbI}_{3-x} \mathrm{Cl}_{x}$ " perovskite. Adv. Funct. Mater. 24, 7102 (2014).

41. G.E. Eperon, S.D. Stranks, C. Menelaou, M.B. Johnston, L.M. Herz, and H.J. Snaith: Formamidinium lead trihalide: A broadly tunable perovskite for efficient planar heterojunction solar cells. Energy Environ. Sci. 7, 982 (2014).

42. J-H. Im, J. Chung, S-J. Kim, and N-G. Park: Synthesis, structure, and photovoltaic property of a nanocrystalline $2 \mathrm{H}$ perovskite-type novel sensitizer $\left(\mathrm{CH}_{3} \mathrm{CH}_{2} \mathrm{NH}_{3}\right) \mathrm{PbI}_{3}$. Nanoscale Res. Lett. 7, 353 (2012).

43. F.X. Xie, D. Zhang, H. Su, X. Ren, K.S. Wong, M. Grätzel, and W.C.H. Choy: Vacuum-assisted thermal annealing of $\mathrm{CH}_{3} \mathrm{NH}_{3} \mathrm{PbI}_{3}$ for highly stable and efficient perovskite solar cells. ACS Nano 9, 639 (2015).

44. N. Onoda-Yamamuro, T. Matsuo, and H. Suga: Calorimetric and IR spectroscopic studies of phase transitions in methylammonium trihalogenoplumbates (II) $\dagger$. J. Phys. Chem. Solids 51, 1383 (1990).

45. R.E. Wasylishen, O. Knop, and J.B. Macdonald: Cation rotation in methylammonium lead halides. Solid State Commun. 56, 581 (1985).

46. J.M. Frost, K.T. Butler, F. Brivio, C.H. Hendon, M. van Schilfgaarde, and A. Walsh: Atomistic origins of high-performance in hybrid halide perovskite solar cells. Nano Lett. 14, 2584 (2014).

47. N.J. Jeon, J.H. Noh, W.S. Yang, Y.C. Kim, S. Ryu, J. Seo, and S.I. Seok: Compositional engineering of perovskite materials for high-performance solar cells. Nature 517, 476 (2015).

48. K.K. Bass, R.E. McAnally, S. Zhou, P.I. Djurovich, M. Thompson, and B. Melot: Influence of moisture on the preparation, crystal structure, and photophysical properties of organohalide perovskites. Chem. Commun. 50, 15819 (2014).

\section{Supplementary Material}

To view supplementary material for this article, please visit http://dx.doi.org/10.1557/jmr.2016.272.

Experimental methods additional details, structural confirmation using 2D x-ray diffraction and comparison to OD scanned spectra, CVD perovskite data, additional XPS, additional XRD data, peak parameters for (110) and (220) perovskite peaks, depth profiling atomic ratios. 